\title{
ENHANCING ROOF CONSTRUCTION TO IMPROVE EFFICIENCY OF DRYING
}

\author{
Emils Avots ${ }^{1}$, Janis Palabinskis ${ }^{1}$, Aivars Aboltins ${ }^{1}$, Algirdas Jasinskas ${ }^{2}$ \\ ${ }^{1}$ Latvia University of Life Sciences and Technologies, Latvia; \\ ${ }^{2}$ Aleksandras Stulginskis University, Lithuania \\ emils.avots@inbox.lv, janis.palabinskis@1lu.lv, aivars.aboltins@inbox.lv, algirdas.jasinskas@asu.lt
}

\begin{abstract}
Due to different conditions, this kind of collectors has not been implemented often. Firstly, it is an intervention in the roof construction, which requires changes to the projects, additional materials and expenses. Secondly, most importantly, the manifold absorbent material was not durable (damaged by sunlight, weather, birds, etc.) and over time became dirty and lost its transparency. Some of the disadvantages discussed above can be prevented by constructing a substructure that would capture the heated air under the roof of the hangar and direct it to the drying object. The design would be protected from precipitation, direct sunlight and birds.In this way, the heated air can be usedto cool the grain or diverted to the furnace as a preheated air.The simple construction on the roof of the hangar shows that using such a design it is possible to increase the temperature of the usable air to $5{ }^{\circ} \mathrm{C}$. The article offers a technological and technical solution for the use of warm air of the hangar for active ventilation of grain in the drying bin, which will significantly increase the efficiency of drying grain.
\end{abstract}

Keywords: roof construction, air heating, drying, efficiency.

\section{Introduction}

Modern new grain pre-treatment points, which are designed on the basis of heat and high-capacity grain storage bins, practically do not focus on the use of renewable energy. If renewable energy resources can be used as heat sources in renewable energy resources, then the use of wood resources for heat production is virtually impossible for other drying installations. The hangars, which are universal farm buildings were earlier recommended, but few realized, due to relatively short longevity to construct air heating solar collectors on the roof that could heat up the grain used for drying the air.

Solar radiation is an alternative source of energy for heat recovery for drying of various agricultural products, such as fruit, vegetables and cereal products. To get heat from solar radiation, solar collectors are used.

Wall and floor panels are used to heat production and other premises, which absorb solar heat and heat up the indoor air. This system is simple, efficient, inexpensive and environmentally friendly. Such a system is capable of providing fresh air and increasing the temperature of indoor temperatures by 5 to $25^{\circ} \mathrm{C}$ above ambient air temperature, thus saving 20-70 \% of fuel energy [1].

The territory of Latvia has a relatively low intensity of solar radiation. Its total solar energy is $1000-1200 \mathrm{kWh} \cdot \mathrm{m}^{-2}$ per year.Solar energy is a relatively reliable source of energy, and its disappearance is not forecasted in the future, and is actively used from small households to large factories [2].

It is known that atmospheric air, which is heated in solar collectors and similar equipment, can effectively be used to dry grain by raising the temperature to $15^{\circ} \mathrm{C}$, which means that, during days, solar thermal energy can be used efficiently without the use of fuel fueled heat generators [3]. Of course, such conditions for drying grain can be provided on sunny days, while the rest of the time it is necessary to use heat generators[4]. Solar collectors are widely used for electricity generation, but air heating is less common, although the design is relatively simple and inexpensive.

Collector insulation plays a large role in solar collectors for heating air. The collectors with insulated surfaces and uninsulated surfaces using thin steel plate as absorbent material warmed up atmospheric air by $10-12{ }^{\circ} \mathrm{C}$ and $5-6^{\circ} \mathrm{C}$, respectively, with solar radiation $800 \mathrm{~W} \cdot \mathrm{m}^{-2}$ [1].

D. Fiaschi and A. Bertolli studied the heat generated from solar radiation from building roofs made of copper sheets with roof-mounted air ducts. It has been shown that by using well-designed geometry pipelines placed under a copper plate, it is possible to obtain an effective solar collector on the roof [5].

Many studies are devoted to drying of herbs and spices using the warm air extracted from roofmounted solar collectors. These collectors function as the roof of a building. 
The effectiveness of drying of different herbs and spices using roof-mounted solar collectors can reach $35 \%$ per day. Such a solar collector roof also protects agricultural products from rain and insects, unlike drying agricultural products in the open sunlight field [6]. Similar studies have been done on drying of pineapples using a roof-mounted solar collector. After drying pineapples for 8 hours, the drying costs accounted for only $20 \%$ of the cost, when drying was done using an electric drying machine [7].

Offering a roof-mounted solar collector it is possible to obtain a quality-dried product at a much shorter time than if these herbs are dried out in the field under the influence of solar radiation. The heated air is collected in the roof top and then further by the fan to the dryer. The payback time for this roof construction is approximately 5 years. The results of modeling simulation coincide with the performed drying experiments [8].

A roof-mounted air-cooled solar collector system is provided with heaters and fans, which can be used depending on the climatic conditions $[9 ; 10]$.

The article deals with a simple warm-air collection system and its performance analysis to increase the temperature of the air supplied to the grain drying bin.

\section{Materials and methods}

The aim of this study is to make an air collector and to study the heat extraction using the air drawn from the hangar roof ridge. Studies were carried out on a farm. The hangar dimensions are $36 \times 20 \mathrm{~m}$ with an area of $720 \mathrm{~m}^{2}$. The hangar walls have a height of $5 \mathrm{~m}$ and a ridge height of $7 \mathrm{~m}$. The outer walls of the hangar and the roof are covered with profiled metal sheets $1 \mathrm{~mm}$ thick. The roof sheet colour is dark brown. Due to the influence of the sun the roof of the hangar absorbs a large amount of heat energy, where the temperature in the ridge on sunny days can increase by $10{ }^{\circ} \mathrm{C}$ more than the temperature of the ambient air. During the experiment, in April and May 2016, the temperature of the metal sheet can exceed $40{ }^{\circ} \mathrm{C}$, at solar radiation of $450-704 \mathrm{~W} \mathrm{~m}^{-2}$.

In order to use the heat generated by the sun for drying grain, the warm air of the hangar is used on the farm, which is fed to the drying bin 13 (Fig. 1) next to the hangar with an isolated air channel 5, using a medium pressure centrifugal fan 9 that produces a pressure of up to $3 \mathrm{kPA}$. The fan productivity depends on the pressure caused by the grain layer, which is 35500 to $64500 \mathrm{~m}^{3} \cdot \mathrm{h}^{-1}$ [11]. The length of the insulated air transmission channel is $13 \mathrm{~m}$ and its diameter is $1 \mathrm{~m}$, and it is connected to the hangar and the annex of the drying bin, thus delivering the air to the drying bin.

Before upgrading the roof structure, using a centrifugal fan 9 the warm air was directed from the hangar 1 through the insulated air duct 5 at connection 4 to the grain drying bin 13 (Fig. 1).

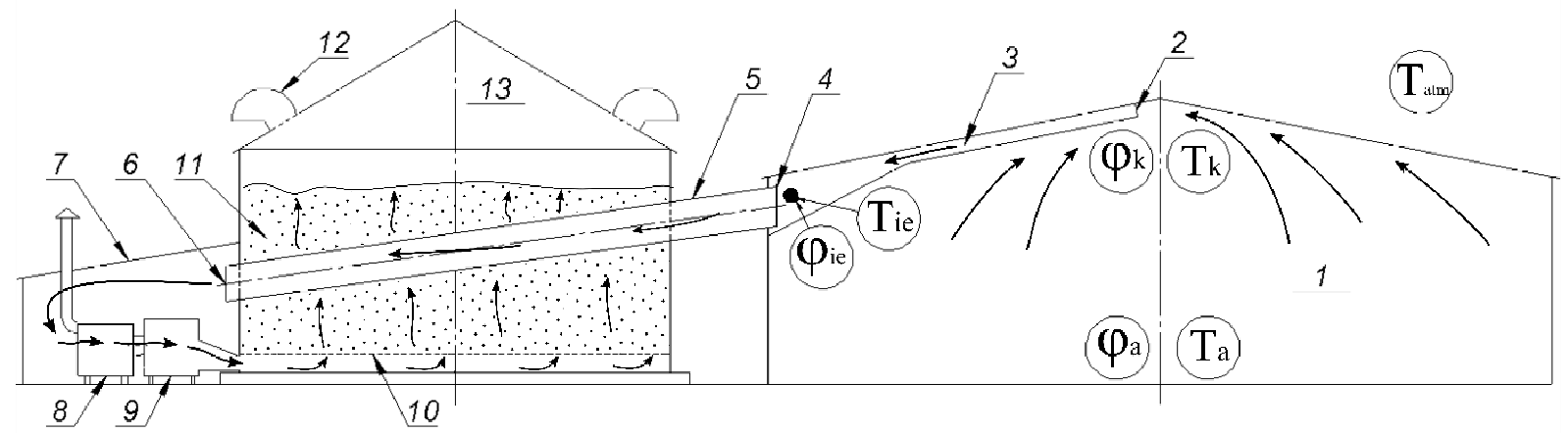

Fig. 1. Airflow from hangar to grain bin with air collection channel: 1 - hangar; 2 -inlet of the air collection channel; 3 - air collection channel; 4 - insulated air channel connection; 5 - insulated duct;

6 - insulated air channel connection at annex; 7 - annex; 8 - heat generator; 9 - centrifugal fan;

10 - perforated floor; 11 - grain layer; 12 - ventilation hatches; 13 - grain drying bin;

$T_{k}$ - air temperature in the hangar top; $T_{a}$ - air temperature in the hangar; $T_{a t m}-$ ambient air temperature; $T_{i e}$ - temperature in the outlet of the air collection channel; $\varphi_{k}$ - air relative humidity in the hangar top; $\varphi_{a}$ - air relative humidity in the hangar; $\varphi_{a t m}-$ ambient air relative humidity; $\varphi_{i e}$ - relative humidity in the connection between insulated ductand air collection channel 
With the help of smoke and the fan turned on, it was found that warm air near the roof of the hangar does not reach the entrance to the air collection channel 4. Therefore, an experimental lightweight construction hot air collection channel was constructed below the roof 3 (Fig. 1, 2), collecting warm air from the hangar's ridge. When temperature of the roof rises, the warm air moves along the roof to the ridge. By creating an air collection channel 3, it is possible to collect heat from the hangar ridge for drying, which is heated by the sun.

Wooden laths of a size $5 \times 5 \mathrm{~cm}$ and a polyethylene film $0.2 \mathrm{~mm}$ thick are used for the construction of the air channel (Fig. 2). The size of the air channel is $9.7 \times 2.7 \times 0.5 \mathrm{~m}$ and area is $23.23 \mathrm{~m}^{2}$. The size of the inlet of the air collection channel is $2.7 \mathrm{x} 0.5 \mathrm{~m}$ with area $1.35 \mathrm{~m}^{2}$. The design of the air collection channel is stable, light and does not pose a large load on the roof structures of the hangar.

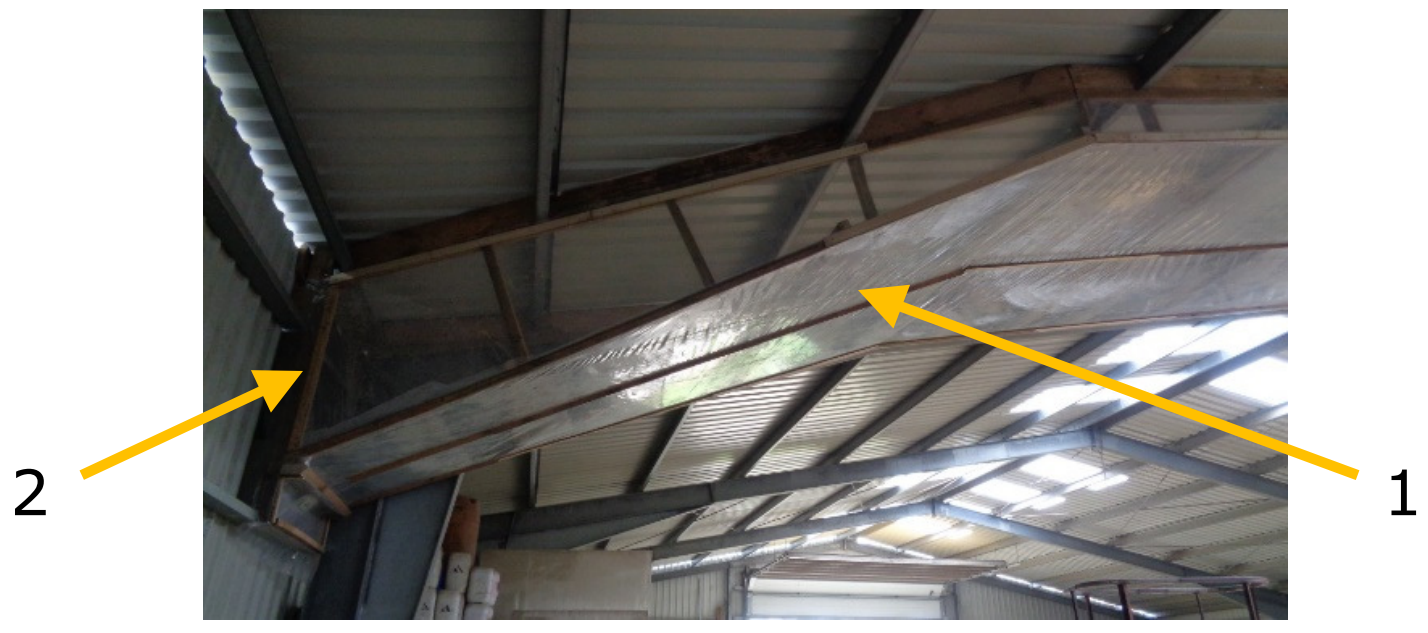

Fig. 2. Air collecting channel covered with polyethylene film: 1 - air collection channel;

2 - connection between the duct and air collection channel

For air temperature and air relative humidity measurements wireless temperature and humidity meters were used such as KLIMA-MONITOR (measurement range for temperature $0{ }^{\circ} \mathrm{C}$ to $+60{ }^{\circ} \mathrm{C}$, air relative humidity $20-99 \%$ and accuracy respectively $\pm 1{ }^{\circ} \mathrm{C}$ and $\pm 5 \%$ ) and Wireless ThermoHygrometer (measurement range for temperature $-40{ }^{\circ} \mathrm{C}$ to $+60{ }^{\circ} \mathrm{C}$, air relative humidity 10 to $99 \%$ and accuracy respectively $\pm 1^{\circ} \mathrm{C}$ and $\pm 5 \%$ ).

The radiation from the sun was determined by a solar radiation meter Power Meter STANDARD ST-1307 (measurement range $0-1999 \mathrm{~W} \cdot \mathrm{m}^{-2}$ and accuracy $10 \mathrm{~W} \cdot \mathrm{m}^{-2}$ ).

The study carried out measurements of the relative humidity of the air temperature $T$ and air in the hangar of $\varphi$ (Fig. 1) at a height of $1 \mathrm{~m}$ from the floor $T_{a}$ and $\varphi_{a}$, at a distance of $30 \mathrm{~cm}$ from the roof cover $T_{k}$ and $\varphi_{k}$, at the entrance to the insulated air passageway $T_{i e}$ and $\varphi_{i e}$ and atmospheric air outside the hangar $T_{a t m}$ and $\varphi_{a t m}$.

\section{Results and discussion}

The studies were carried out in the spring of 2016 in the months of April and May. Measurements of the air relative humidity and temperature were made with the fan turned on in sunny time, so that the clouds do not significantly affect solar radiation. To show the degree of heated air, measurements were compared with the temperature in the hangar at a height of $1 \mathrm{~m}$ from the floor. The results are summarized in Fig. 3-6.

Figures 3 and 4 compare the air temperature difference without using and using an air collection channel. Comparing the results the temperature of the collected air for drying in the air collection duct is only $2-3{ }^{\circ} \mathrm{C}$ lower than in the ridge $T_{k}$, while without the duct it is even lower by $8{ }^{\circ} \mathrm{C}$ (Fig. 4 ). Without using the air collection channel, the average temperature difference between the hangar ridge $T_{k}$ and the hangar's air $T_{a}$ is high, from 5.8 to $8.8^{\circ} \mathrm{C}$, resulting in incomplete use of warm air in the ridge (Fig. 3). The temperature difference between the insulated air channel entrance $T_{i e}$ and the hangar $T_{a}$ is relatively small, from 0.6 to $1.1^{\circ} \mathrm{C}$, so the benefits of the sun's influence on the heated air 
atmosphere in the hangar is minimal. In turn, the average solar radiation during the experiments ranges from 450 to $620 \mathrm{~W} \cdot \mathrm{m}^{-2}$.

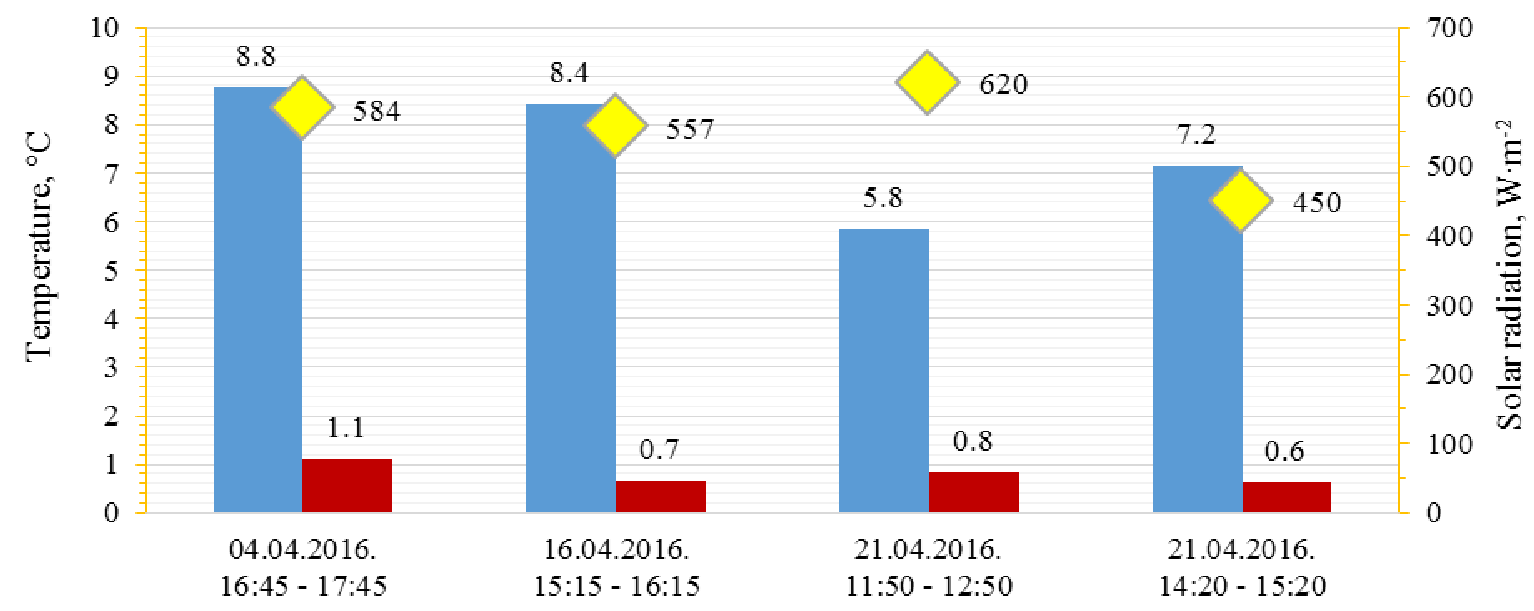

- Avarage temperature difference between $\mathrm{Tk}$ and $\mathrm{Ta}$

Date, time

- Avarage temperature difference between Tie and Ta

Avarage solar radiation

Fig. 3. Comparison of average temperature differences without using air collection channel

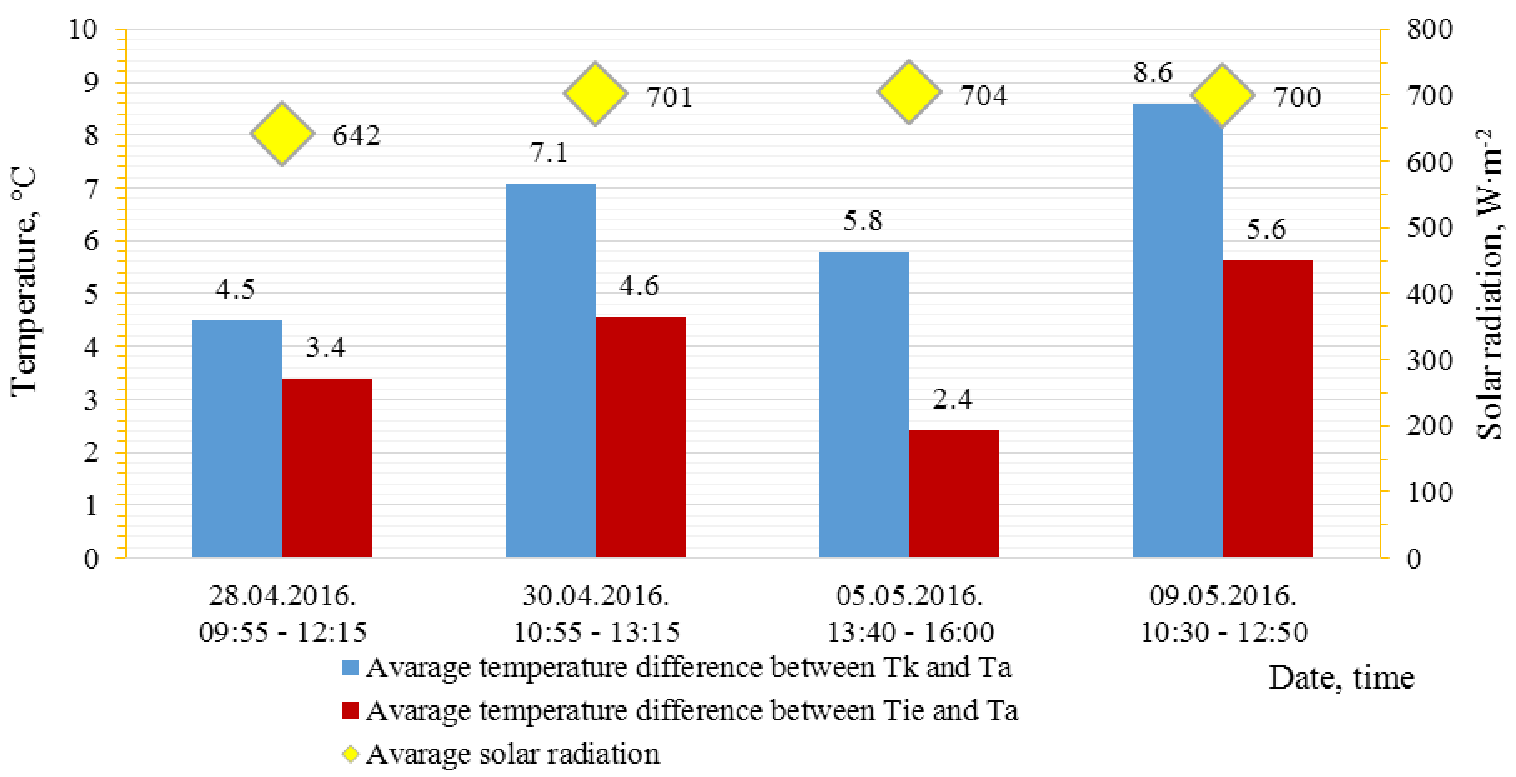

Fig. 4. Comparison of average temperature differences using air collection channel

Using the air collection channel, the temperature difference between the air collection channel entrance $T_{i e}$ and the hangar $T_{a}$ has increased by an average of $3.2^{\circ} \mathrm{C}$, and on some days this difference exceeds up to $5{ }^{\circ} \mathrm{C}$ (Fig. 4). This means that warm air is collected more efficiently from the ridge of the hangar, where its temperature is higher. In addition, the temperature difference between the ridge of the hangar $T_{k}$ and hangar $T_{a}$ is lower, which is an average of $6.5^{\circ} \mathrm{C}$.

In addition, the influence of the weather conditions during the measurement is also to be taken into account, since, as shown in Fig. 3 and 4, the radiation of the sun was by 642 to $704 \mathrm{~W} \cdot \mathrm{m}^{-2}$. Atmospheric air and air in the hangar are warmed up, so there is a lower temperature difference between the ridge of the hangar $T_{k}$ and the hangar $T_{a}$.

Similar to the temperature differences, the relative humidity of the air between the ridge of the hangar $\varphi_{k}$ and the hangar $\varphi_{a}$ is high, which ranged from 21 to $28 \%$ during the experiment, without 
using the air collection channel. This means that the humidity of the hangar ridge was more than $20 \%$ less than the hangar.

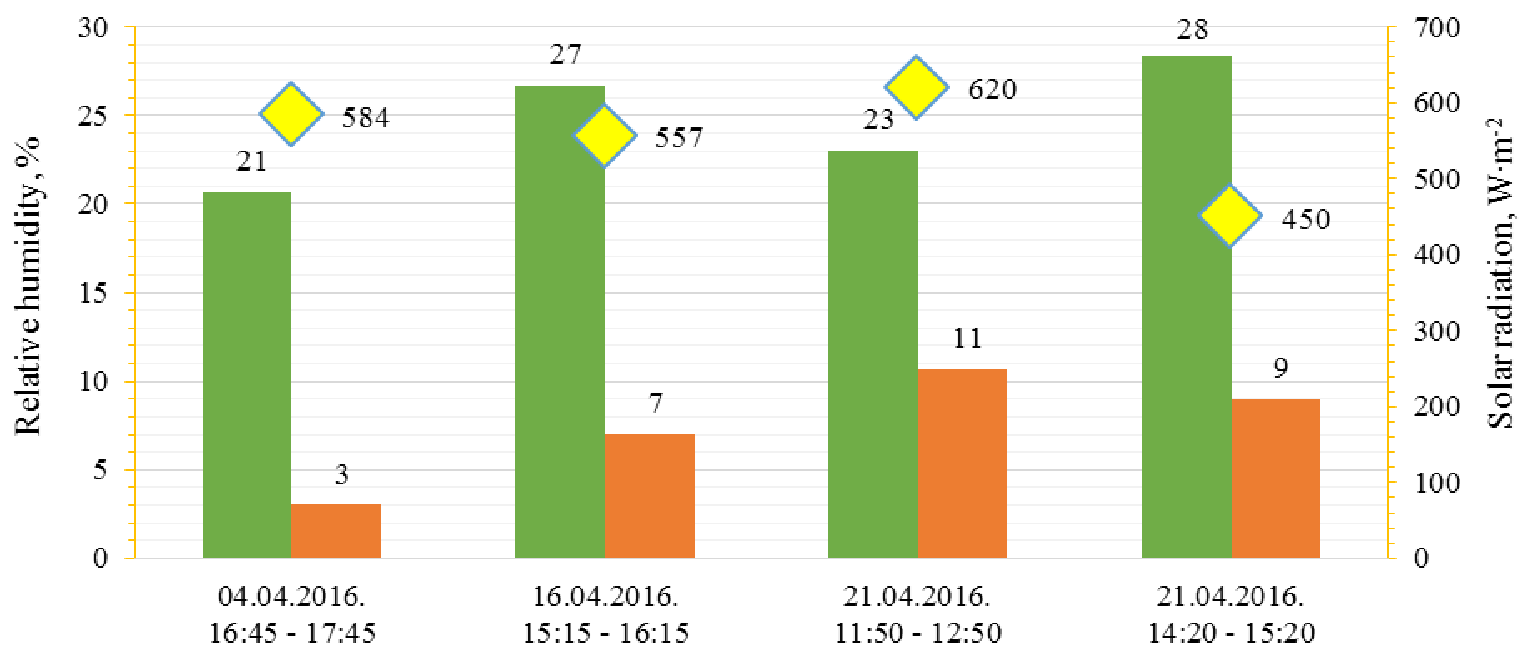

- Avarage relative humidity difference between $\varphi \mathrm{k}$ and $\varphi \mathrm{a}$

Date, time

Avarage relative humidity difference between $\varphi$ ie and $\varphi$ a

$\checkmark$ Avarage solar radiation

Fig. 5. Comparison of average relative humidity differences without using air collection channel

However, the relative humidity of the air at the entrance to the air channel decreased slightly, as the relative humidity of the air between the hangar $\varphi_{a}$ and the inlet of the air collection channel $\varphi_{i e}$ was observed, although the temperature difference was observed only at $1{ }^{\circ} \mathrm{C}$. This effect can be explained by the air flow generated by the fan, because the airflow can significantly change the air parameters.

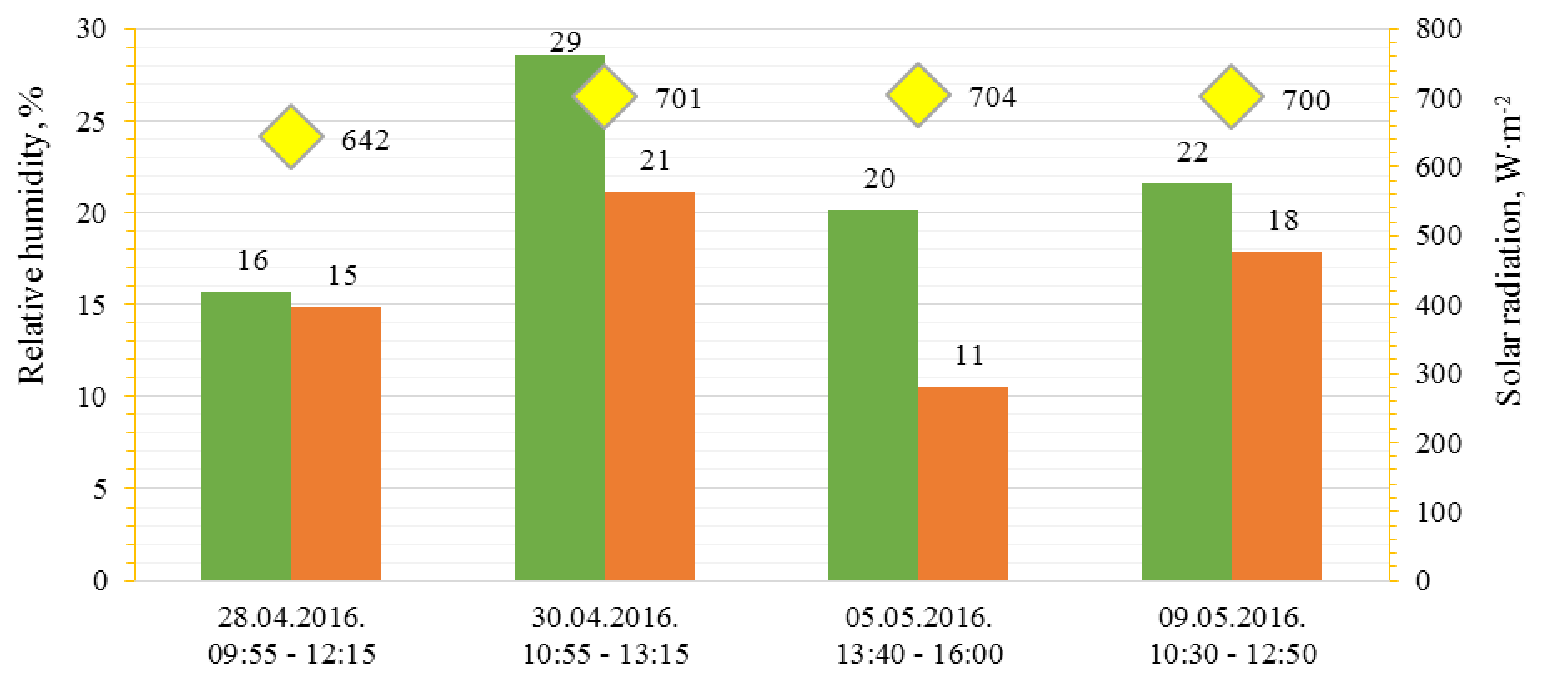

- Avarage relative humidity difference between $\varphi \mathrm{k}$ and $\varphi \mathrm{a}$

- Avarage relative humidity difference between $\varphi$ ie and $\varphi$ a

Date, time

Avarage solar radiation

Fig. 6. Comparison of average relative humidity differences using air collection channel

Using the air collection channel, it was observed that the relative humidity of the air between the ridge of the hangar $\varphi_{k}$ and the hangar $\varphi_{a}$ was between 16 and $29 \%$, which means that the relative humidity in the ridge $\varphi_{k}$ was still lower than in the hangar, just as in the previous measurements carried out. During these measurements, solar radiation was also slightly higher, on average from 642 to $704 \mathrm{~W} \cdot \mathrm{m}^{-2}$.

In contrast, the average temperature difference between the inlet of the insulated air channel $T_{i e}$ and the hangar $T_{a}$ increased with the use of an air collection channel, which means that air from the ridge of the hangar is collected more efficiently and directed to the grain dryer. This is illustrated by 
the difference in air relative humidity between the insulated air channel inlet and the hangar, which in this case ranged from 11 to $21 \%$. Compared to Fig. 5 air relative humidity differences, it can be seen that it is possible to reduce the relative humidity of air by about 2 times and to use it better for drying of agricultural products (Fig. 5, 6), using an air collection channel.

Assuming that the drying air temperature is increased by $4{ }^{\circ} \mathrm{C}$ using an air collection channel, the amount of heat that was saved is calculated and compared with the fuel consumption, where the amount of heat generated by diesel is $4.14 \cdot 10^{7} \mathrm{~J} \cdot \mathrm{kg}^{-1}$. It saves $332.8 \mathrm{MJ}$ of energy equivalent to $8 \mathrm{~kg}$ of fuel oil per hour. So, using a warm air collection channel that increases the incoming air temperature by $4{ }^{\circ} \mathrm{C}$, it saves 9.6 liters of diesel fuel during one hour of drying.

\section{Conclusions}

1. Using a simple air collection system, the internal air temperature of the hangar can be used more effectively during the drying process. In good weather conditions, the temperature of the drying can increase up to $6^{\circ} \mathrm{C}$.

2. Using the air collection duct, the fuel consumption for heating the drying air temperature decreases by 9.6 liters per hour.

3. Wider use of solar energy with simple equipment can make a significant contribution to energy efficiency, especially in processes that require high-energy intensity.

\section{References}

[1] Ruskis G., Aboltins A., Palabinskis J. Steel-Tinplate as a Solar Wall Panel and Its Effectiveness. Journal of Energy and Power Engineering, vol. 6, Number 6, 2012, pp. 912-915.

[2] Saules enerǵijas izmantošana pasaulē un Latvijā (Use of solar energy in the world and in Latvia). (In Latvian). [online] [26.03.2018]. Available at: http://www.picaso.lv/nozares-jaunumi/86saules-enerijas-izmantoana

[3] Lauva A., Aboltiņš A., Palabinskis J., Sadigova N. K. Movable air solar collector and its efficiency. Engineering for Rural Development. Proceedings of the 7th International Scientific Conference, Jelgava, Latvia, 29-30 May, 2008. pp. 51-56.

[4] Solar pre-heat chamber for grain dryers. Martin H. Tonn (inventor). Int. CI. F24J 3/02. Publication date. 18.11.1975. Pub. No. US 3919784 A

[5] Fiaschi D., Bertolli A. Design and exergy analysis of solar roofs: A viable solution with esthetic appeal to collect solar heat. Renewable Energy, 46, 2012. pp. 60-71.

[6] Janjai S., Tung P. Performance of a solar dryer using hot air from roof-integrated solar collectors for drying herbs and spices. Renewable Energy, 30(14), 2005. pp. 2085-2095.

[7] Sreekumar A. Techno-economic analysis of a roof-integrated solar air heating system for drying fruit and vegetables. Energy Conversion and Management, 51(11), 2010. pp. 2230-2238.

[8] Janjai S., Srisittipokakun N., Bala B. K. Experimental and modelling performances of a roofintegrated solar drying system for drying herbs and spices. Energy, 33(1), 2008. pp. 91-103.

[9] Fudholi A., Othman M. Y., Ruslan M. H., Yahya M., Zaharim A., Sopian K. Design and testing of solar dryer for drying kinetics of seaweed in Malaysia. Recent Researches in Geography, Geology, Energy, Environment and Biomedicine - Proc. of the 4th WSEAS Int. Conf. on EMESEG'11, 2nd Int. Conf. on WORLD-GEO'11, 5th Int. Conf. on EDEB'11, (July), 2011. pp. 119-124.

[10] Fudholi A., Ruslan M. H., Othman M. Y., MohdAzmi M. S., Zaharim A., Sopian K. Drying of palm oil fronds in solar dryer with finned double-pass solar collectors. WSEAS Transactions on Heat and Mass Transfer, 7(4), 2012. pp. 105-114.

[11] NECO CENTRIFUGAL FAN (CE Models). Owner's and Operator's Manual. A Division of GLOBAL Industries, Inc., USA, June 2010. 28 p. 